\title{
Tabulation of an Integral Arising in the Theory of Cooperative Phenomena
}

\section{Michael Tikson ${ }^{1}$}

Integrals of the form

$$
\int_{0}^{\pi} \int_{0}^{\pi} \int_{0}^{\pi} f(3 b-\cos x-\cos y-\cos z) d x d y d z
$$

occur in problems that involve averages over the characteristic values, $\lambda$, of the difference equation

$$
\Delta^{2} \gamma_{l, m, n}=\lambda \gamma_{l, m, n}
$$

(where $\Delta^{2}$ is the Laplacian second difference operator) with periodic boundary conditions

$\gamma_{l, m, n}=\gamma_{l+N, m, n} ; \quad \gamma_{l, m, n}=\gamma_{l, m+N, n} ; \gamma_{l, m, n}=\gamma_{l, m, n+N}$.

Such averages arise in the theory of ferromagnetism, cooperative phenomena in solids, and critical fluctuations in liquids.

In this paper, we deal with the tabulation of

$$
I(b)=\frac{1}{\pi^{3}} \int_{0}^{\pi} \int_{0}^{\pi} \int_{0}^{\pi} \frac{d x d y d z}{3 b-(\cos x+\cos y+\cos z)}
$$

$[1]^{2}$ for $b^{-1}=\mu=.01(.01) 1$.

To obtain $I(b)$ for values of $\mu$ from .01 to .8 , we represent (4) as a power series in $\mu$ by the use of the following relations [1]:

$$
\begin{aligned}
\int_{0}^{\pi} & \int_{0}^{\pi} \int_{0}^{\pi}(\cos x+\cos y+\cos z)^{n} d x d y d z \\
& =\left[\frac{\partial^{n}}{\partial a^{n}} \int_{0}^{\pi} \int_{0}^{\pi} \int_{0}^{\pi} e^{a(\cos x+\cos y+\cos z)} d x d y d z\right]_{a=0} \\
& =\left[\frac{\partial^{n}}{\partial a^{n}}\left\{\int_{0}^{\pi} e^{a \cos w} d w\right\}^{3}\right]_{a=0}=\pi^{3}\left[\frac{\partial^{n}}{\partial a^{n}}\left\{I_{0}(a)\right\}^{3}\right]_{a=0}
\end{aligned}
$$

where $I_{0}(a)$ is the Bessel function of order zero for imaginary argument, which is given by the series

$$
I_{0}(a)=\sum_{k=0}^{\infty} \frac{\left(\frac{a}{2}\right)^{2 k}}{(k !)^{2}} .
$$

1 Computation Research Section, Flight Research Laboratory, Wright Air Development Center, USAF. The present computation was performed with the assistance of various members of the Computation. Laboratory of the National Bureau of Standards, where the author was a guest worker.

${ }_{2}$ Figures in brackets indicate the literature references at the end of this pap er.
We obtain

$$
I(b)=\frac{\mu}{3} \sum_{k=0}^{\infty}\left(\frac{1}{3}\right)^{2 m}(2 m) ! c_{2 m} \mu^{2 m}
$$

where the $c_{2 m}$ are defined by

$$
\left[I_{0}(x)\right]^{3}=\sum_{0}^{\infty} c_{2 m} x^{2 m}
$$

a tabulation of $c_{2 m} \quad(m=0,1, \ldots, 20)$ is given in table 1 .

$$
\text { TABLE 1. }{ }^{\text {a }} \text { Coefflcients of }\left[I_{0}(x)\right]^{3}=\sum_{0}^{\infty} c_{2 m} x^{2 m}
$$

Numbers in parentheses stand for the number of zeros between the decimal point and the first significant figure.

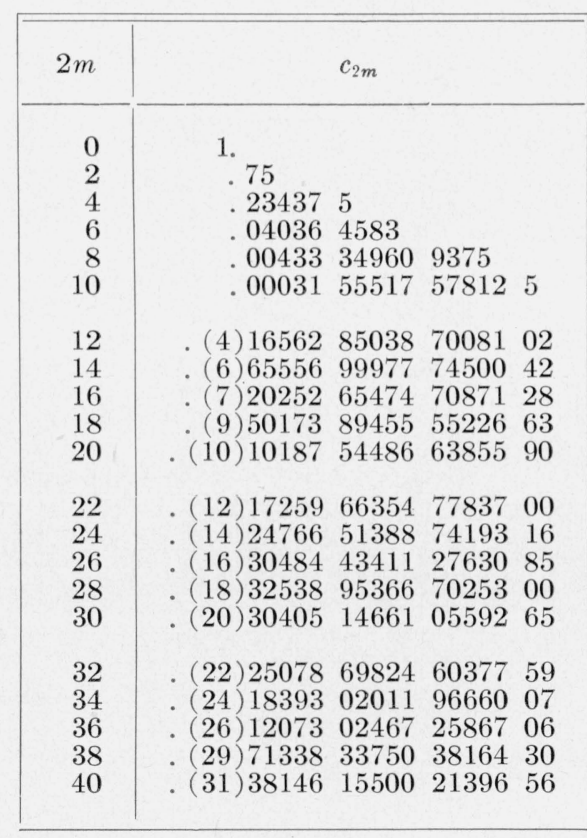

a Although the number of significant figures given here is many more than was required in the calculations for table 2, there may be some general interest in having these coefficients of $\left[I_{0}(x)\right]^{3}$ available to many places.

At most the first 21 terms of (7) were used to obtain 80 values of $I(b)$ correct to five decimal places. The convergence of (7) is too slow to be used as a practical means of obtaining values of $I(b)$ beyond $\mu=.8$.

The remaining values of $I(b)$ given in the table 2 were obtained by numerical integration. Since the integrand of (4) is infinite for $x=y=z=0$ and $b=1$, 
TABLE 2. $I(b)$

\begin{tabular}{|c|c|c|c|}
\hline$\mu=b^{-1}$ & $I(b)$ & $\mu=b^{-1}$ & $I(b)$ \\
\hline $\begin{array}{r}.01 \\
.02 \\
.03 \\
.04 \\
.05\end{array}$ & $\begin{array}{r}0.00333 \\
.00667 \\
.01000 \\
.01334 \\
.01667\end{array}$ & $\begin{array}{l}.51 \\
.52 \\
.53 \\
.54 \\
.55\end{array}$ & $\begin{array}{r}0.17831 \\
.18219 \\
.18610 \\
.19003 \\
.19400\end{array}$ \\
\hline $\begin{array}{r}.06 \\
.07 \\
.08 \\
.09 \\
.10\end{array}$ & $\begin{array}{r}.02001 \\
.02335 \\
.02670 \\
.03004 \\
.03339\end{array}$ & $\begin{array}{l}.56 \\
.57 \\
.58 \\
.59 \\
.60\end{array}$ & $\begin{array}{r}19799 \\
.20202 \\
.20607 \\
.21017 \\
.21429\end{array}$ \\
\hline $\begin{array}{l}11 \\
.12 \\
13 \\
.14 \\
.15\end{array}$ & $\begin{array}{r}03674 \\
.04010 \\
.04346 \\
.04682 \\
.05019\end{array}$ & $\begin{array}{r}61 \\
.62 \\
.63 \\
.64 \\
.65\end{array}$ & $\begin{array}{r}.21846 \\
.22266 \\
.22691 \\
.23120 \\
.23553\end{array}$ \\
\hline $\begin{array}{l}16 \\
.17 \\
18 \\
.19 \\
20\end{array}$ & $\begin{array}{r}05356 \\
.05694 \\
.06033 \\
.06372 \\
.06712\end{array}$ & $\begin{array}{r}.66 \\
.67 \\
.68 \\
.69 \\
.70\end{array}$ & $\begin{array}{r}23991 \\
.24434 \\
.24882 \\
.25335 \\
.25794\end{array}$ \\
\hline $\begin{array}{l}.21 \\
.22 \\
23 \\
.24 \\
.25\end{array}$ & $\begin{array}{r}07052 \\
07394 \\
07736 \\
.08079 \\
08422\end{array}$ & $\begin{array}{r}.71 \\
.72 \\
.73 \\
.74 \\
.75\end{array}$ & $\begin{array}{l}26259 \\
.26730 \\
.27208 \\
.27694 \\
.28186\end{array}$ \\
\hline $\begin{array}{l}26 \\
27 \\
28 \\
.29 \\
.30\end{array}$ & $\begin{array}{r}08767 \\
.09113 \\
.09459 \\
.09807 \\
.10156\end{array}$ & $\begin{array}{r}.76 \\
.77 \\
.78 \\
.79 \\
.80\end{array}$ & $\begin{array}{r}.28687 \\
.29196 \\
.29714 \\
.30242 \\
.30781\end{array}$ \\
\hline $\begin{array}{l}.31 \\
32 \\
33 \\
.34 \\
.35\end{array}$ & $\begin{array}{r}10506 \\
.10857 \\
.11209 \\
.11563 \\
.11918\end{array}$ & $\begin{array}{l}.81 \\
82 \\
.83 \\
.84 \\
.85\end{array}$ & $\begin{array}{r}31332 \\
.31894 \\
.32469 \\
.33057 \\
.33662\end{array}$ \\
\hline $\begin{array}{l}36 \\
37 \\
38 \\
.39 \\
.40\end{array}$ & $\begin{array}{r}12274 \\
.12632 \\
.12992 \\
.13352 \\
.13715\end{array}$ & $\begin{array}{l}86 \\
87 \\
.88 \\
.89 \\
.90\end{array}$ & $\begin{array}{r}34284 \\
.34925 \\
.35589 \\
.36277 \\
.36993\end{array}$ \\
\hline $\begin{array}{l}.41 \\
.42 \\
43 \\
.44 \\
.45\end{array}$ & $\begin{array}{r}14079 \\
.14445 \\
.14813 \\
.15183 \\
.15555\end{array}$ & $\begin{array}{l}91 \\
92 \\
.93 \\
94 \\
.95\end{array}$ & $\begin{array}{r}.37741 \\
.38526 \\
.39355 \\
.40238 \\
.41189\end{array}$ \\
\hline $\begin{array}{l}.46 \\
.47 \\
.48 \\
.49 \\
.50\end{array}$ & $\begin{array}{r}15929 \\
.16304 \\
.16683 \\
.17063 \\
.17446\end{array}$ & $\begin{array}{r}.96 \\
.97 \\
.98 \\
.99 \\
1.00\end{array}$ & $\begin{array}{r}.42229 \\
.43395 \\
.44758 \\
.46503 \\
.50546\end{array}$ \\
\hline
\end{tabular}

some modification was necessary before numerical integration could be applied. We make use of (4) in the form:

$$
I(b)=\frac{1}{\pi^{2}} \int_{0}^{\pi} \frac{2}{3 b-\cos x} K\left(\frac{2}{3 b-\cos x}\right) d x,
$$

where $K$ is the complete elliptic integral of the first kind defined by

$$
K(u)=\int_{0}^{\frac{\pi}{2}} \frac{d \theta}{\sqrt{1-u^{2} \sin ^{2} \theta}} .
$$

In carrying out the integration, the integrand in (9) was expressed as the sum of two parts. The first part was the integrand diminished by an expression that removed the singularity and made the numerical integration feasible. This expression was so chosen that it could be integrated in closed form.

As an alternative to the foregoing method, the following procedure was employed as a check on some of the results. If we substitute the series expansion for $K(u)$ in (9) and invert the order of summation and integration, we obtain ultimately

$$
I(b)=\left(9 b^{2}-1\right)^{-\frac{1}{2}}+\sum_{n=1}^{\infty}\left[\frac{1 \cdot 3 \cdot 5 \cdots(2 n-1)}{2 \cdot 4 \cdot 6 \cdots(2 n)}\right]^{2} \frac{2^{2 n} g_{2 n}}{(2 n) !}
$$

where $g_{n}=\left[d^{n} / d^{n}(3 b)\right]\left\{\left[9 b^{2}-1\right]^{-\frac{1}{2}}\right\}$. We note that $g_{n}$ satisfies the following recurrence relation

$$
\left(9 b^{2}-1\right) g_{n+1}+3 b(2 n+1) g_{n}+n^{2} g_{n-1}=0 .
$$

[1] E. W. Montroll, Nuovo Cimento, [9] 6, 265 (1941)

[2] G. N. Watson, Quart. J. Mathematics 10, 266 (Oxford 1939)

[3] E. Jahnke and F. Emde, Funktionentafeln mit Formeln und Kurven, 2d ed, p. 145 (1909).

[4] H. B. Dwight, Tables of integrals and other mathematical data, p. 123 (Macmillan Co., New York, N. Y., 1947).

[5] T.H. Berlin and M. Kac, The spherical model of a ferromagnet, Johns Hopkins University, ONR Report N60 NR-293, Task Order 18, and N60 NR-246, Task Order 5 .

Washington, November 26, 1952. 